\title{
Peripheral Muscle Microcirculatory Alterations in Patients With Pulmonary Arterial Hypertension: A Pilot Study
}

\author{
Stavros Dimopoulos MD, Georgios Tzanis MD, Christos Manetos MD, Athanasios Tasoulis MD, \\ Anthi Mpouchla MD, Eleni Tseliou MD, Ioannis Vasileiadis MD, Nikos Diakos MD, \\ John Terrovitis MD, and Serafim Nanas MD
}

BACKGROUND: Pulmonary microcirculation abnormalities are the main determinants of pulmonary arterial hypertension (PAH) pathophysiology. We hypothesized that PAH patients have peripheral tissue microcirculation alterations that might benefit from hyperoxic breathing. We evaluated peripheral muscle microcirculation with near-infrared spectroscopy, before and after hyperoxic breathing. METHODS: Eight PAH subjects, 8 healthy subjects (controls) matched for age, sex, and body mass index, and 16 subjects with chronic heart failure and matched for functional capacity with the PAH subjects underwent near-infrared spectroscopy. Tissue $\mathrm{O}_{2}$ saturation, defined as the hemoglobin saturation $(\%)$ in the microvasculature compartments, was measured on the thenar muscle. Then the 3-min brachial artery occlusion technique was applied before, during, and after $15 \mathrm{~min}$ of breathing $100 \% \mathrm{O}_{2}$. We calculated the oxygen consumption rate $(\% / \mathrm{min})$, the reactive hyperemia time, and the time needed for tissue $\mathrm{O}_{2}$ saturation to reach its baseline value after the release of the occlusion. RESULTS: Compared to the controls, the PAH subjects had a significantly lower resting tissue $\mathrm{O}_{2}$ saturation $(65.8 \pm 14.9 \%$ vs $82.1 \pm 4.0 \%, P=.005)$, a trend toward a lower oxygen consumption rate $(35.3 \pm 9.1 \% / \mathrm{min}$ vs $43.4 \pm 19.7 \% / \mathrm{min}, P=.60)$, and a significantly higher reactive hyperemia time $(3.0 \pm 0.6 \mathrm{~min}$ vs $2.0 \pm 0.3 \mathrm{~min}, P<.001)$. The PAH subjects also had lower tissue $\mathrm{O}_{2}$ saturation $(P=.08)$, lower peripheral arterial oxygen saturation $(P=.01)$, and higher reactive hyperemia time $(P=.02)$ than the chronic heart failure subjects. After hyperoxic breathing, the PAH subjects had increased tissue $\mathrm{O}_{2}$ saturation $(65.8 \pm 14.9 \%$ to $71.4 \pm 14.5 \%, P=.01)$, decreased oxygen consumption rate $(35.3 \pm 9.1 \% / \mathrm{min}$ to $25.1 \pm 6.6 \% / \mathrm{min}$, $P=.01)$, and further increased reactive hyperemia time $(3.0 \pm 0.6 \mathrm{~min}$ to $4.2 \pm 0.7 \mathrm{~min}, P=.007)$. CONCLUSIONS: The PAH subjects had substantial impairments of peripheral muscle microcirculation, decreased tissue $\mathrm{O}_{2}$ saturation (possibly due to hypoxemia), slower reactive hyperemia time, (possibly due to endothelium dysfunction), and peripheral systemic vasoconstriction. Acute hyperoxic breathing improved resting tissue $\mathrm{O}_{2}$ saturation (an expression of higher oxygen delivery) and decreased the oxygen consumption rate and reactive hyperemia time during reperfusion, possibly due to increased oxidative stress and evoked vasoconstriction. Key words: endothelium; microcirculation; near-infrared spectroscopy; oxygen breathing; pulmonary arterial hypertension; hyperoxia. [Respir Care 2013;58(12):2134-2141. (C) 2013 Daedalus Enterprises]

\section{Introduction}

Pulmonary arterial hypertension is (PAH) a life-threatening disease that it is associated with poor prognosis. ${ }^{1}$

Drs Dimopoulos, Tzanis, Manetos, Mpouchla, Vasileiadis, and Nanas are affiliated with the Cardiopulmonary Exercise Testing and Rehabilitation Laboratory, First Critical Care Medicine Department, Evgenidio Hospital, National and Kapodistrian University of Athens; and Drs Tasoulis, Tseliou, Diakos, and Terrovitis, are affiliated with the Third Cardiology
PAH patients are characterized by exercise intolerance, with marked fatigue and dyspnea during exercise, limiting their daily life activity. The profound cardiopulmonary

Department, Laiko Hospital, National and Kapodistrian University of Athens, Athens, Greece.

Dr Dimopoulos presented a version of this paper at the International Conference of the American Thoracic Society, held May 13-18, 2011, in Denver, Colorado. 
abnormalities in PAH lead to chronic hypoxemia and right ventricular failure. ${ }^{2}$

Endothelial cell dysfunction plays an important role in the pulmonary vascular remodeling of PAH. ${ }^{3}$ Increased levels of endothelin-1 and thromboxane, and decreased levels of nitric oxide synthase and prostacyclin increase vessel tone and cause cell proliferation and vasoconstriction in the pulmonary microcirculation, with progressive increase in pulmonary vascular resistance. ${ }^{4-6}$

Remodeling of small pulmonary arteries and pulmonary microcirculation abnormalities are the key elements of PAH pathophysiology; the role of the peripheral systemic microcirculation has been less investigated. Recent interesting studies found that PAH is associated with peripheral endothelial dysfunction. ${ }^{7-9}$

Current treatment for PAH is based mainly on restoring the imbalance between vasoactive mediators and correcting the hypoxemia. ${ }^{10}$ Oxygen therapy relieves the tissue hypoxia and hypoxic pulmonary vasoconstriction, but its effect on the peripheral microcirculation is not yet clearly defined.

Near-infrared spectroscopy with vascular occlusion is a valid, noninvasive technique to evaluate peripheral tissue microcirculation. ${ }^{11-18}$ We hypothesized that PAH patients have systemic peripheral tissue microcirculation alterations that might benefit from oxygen therapy, and we measured peripheral muscle microcirculation with near-infrared spectroscopy in PAH patients before, during, and after hyperoxic breathing. Figure 1 illustrates the scheme for nearinfrared spectroscopy with arterial occlusion in a $\mathrm{PAH}$ subject and in a healthy control subject.

\section{Methods}

This study was approved by our institution's human study committee; the study protocol conforms with the ethics guidelines of the 1975 Declaration of Helsinki, and all stages and aspects of the study conformed with the principles of ethical publishing. ${ }^{19}$

This research was supported by a grant from the National and Kapodistrian University of Athens, Athens, Greece. The authors have disclosed no conflicts of interest.

Correspondence: Stavros Dimopoulos MD, Cardiopulmonary Exercise Testing and Rehabilitation Laboratory, First Critical Care Medicine Department, Evgenidio Hospital, National and Kapodistrian University of Athens, Papadiamantopoulou Street 20, Athens, 11528, Greece. E-mail: a-icu@med.uoa.gr.

DOI: $10.4187 /$ respcare.02113

\section{QUICK LOOK}

\section{Current knowledge}

Pulmonary arterial hypertension (PAH) is a lifethreatening disease associated with a poor prognosis. Remodeling of small pulmonary arteries and pulmonary microcirculation abnormalities are the key elements of PAH pathophysiology.

\section{What this paper contributes to our knowledge}

PAH patients exhibited impaired peripheral muscle microcirculation and decreased tissue oxygen saturation, possibly due to hypoxemia and slower reactive hyperemia time. Breathing 100\% oxygen improved tissue oxygen saturation, due to higher oxygen delivery, but reactive hyperemia time decreased during reperfusion after a 3-min brachial artery occlusion, due to increased oxidative stress and evoked vasoconstriction.

\section{Subjects}

We recruited 8 subjects ( 2 men and 6 women) with stable PAH, 16 subjects with stable systolic chronic heart failure ( 8 ischemia, 8 dilated cardiomyopathy), and 8 healthy subjects. The diagnosis of PAH was confirmed via right-heart catheterization that showed moderate to severe PAH and normal pulmonary capillary wedge pressure, and an echocardiogram that showed normal left-ventricular ejection fraction (Table 1). Right-heart catheterization in the PAH subjects was performed within 1 month of the near-infrared spectroscopy evaluation, as part of their PAH follow-up in our institution. None of the PAH subjects had history/evidence of thromboembolic pulmonary disease on isotope perfusion scanning of the lungs, or other secondary causes of PAH. All the chronic heart failure subjects were stable and on optimal medical treatment, including betablockers, angiotensin-converting-enzyme inhibitors, aldosterone antagonists, and furosemide for at least 3 months. The chronic heart failure group was matched with the PAH group for age, sex, body mass index, and functional exercise capacity (New York Heart Association class).

In the PAH group: 4 subjects had PAH associated with congenital cardiac disease ( 2 had an atrial septal defect surgically corrected, 1 had a common ventricle with transposition of the great vessels, and 1 had an atrial septal defect not surgically corrected); 2 subjects had PAH associated with connective tissue disease (1 systemic lupus erythematosus, and 1 systemic scleroderma); 1 subject had PAH associated with hereditary spherocytosis, without hemolytic anemia (hemoglobin $16.6 \mathrm{~g} / \mathrm{dL}$ ), without thrombocytosis, and with history of splenectomy; and 1 subject 

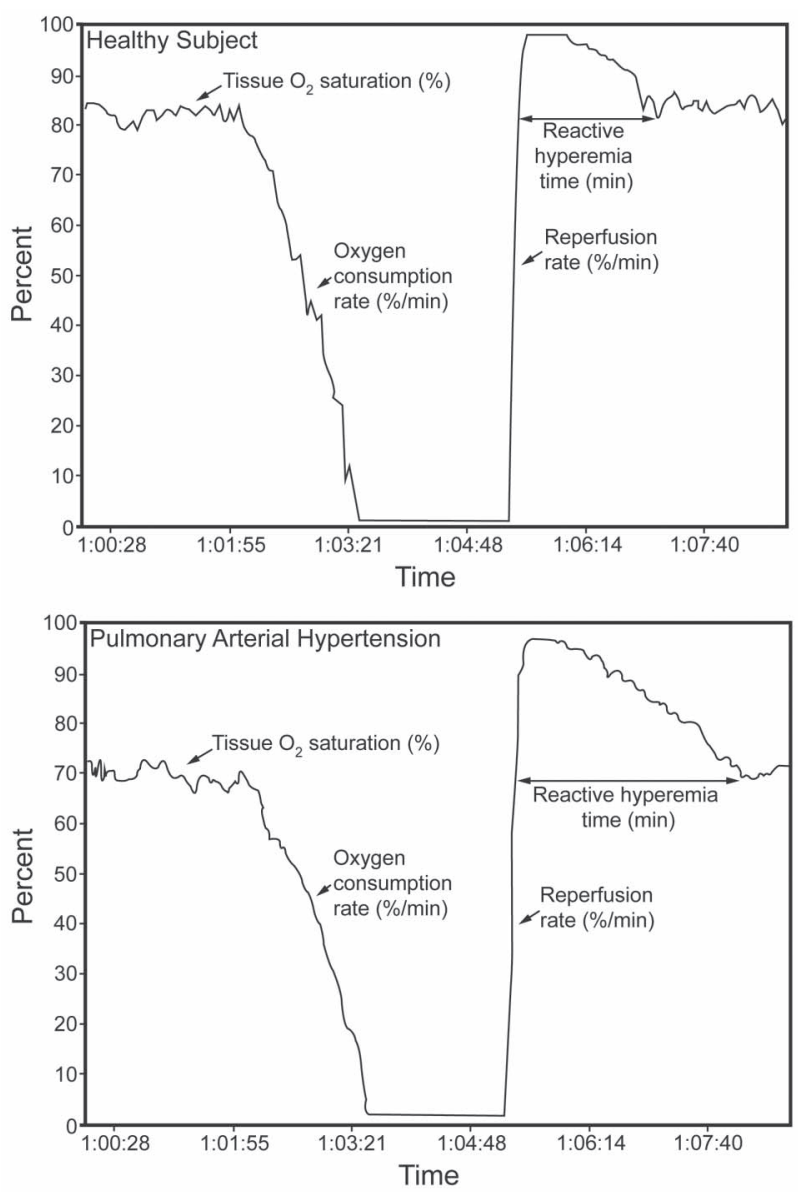

Fig. 1. Example of a tissue oxygenation curve obtained via nearinfrared spectroscopy before, during, and after occlusion of the brachial artery in a healthy subject (upper graph) and in a subject with pulmonary arterial hypertension (lower graph).

had PAH associated with chronic drug abuse. One of the subjects with atrial septal defect had a permanent pacemaker VVI (ventricle paced, ventricle sensed, inhibited pace if beat sensed), implanted 5 years before enrollment in the study, due to complete atrioventricular block. Seven of the PAH subjects had clinical functional capacity of New York Heart Association class II, and one subject was classified as New York Heart Association class III. Seven of the PAH subjects were under treatment with diuretics, 6 with sildenafil, 5 subjects with bosentan, 3 with digoxin, 2 with nifedipine, and 6 with anticoagulants. We excluded people who had a history of smoking, alcohol, diabetes mellitus, systemic arterial hypertension, dyslipidemias, or obesity.

The control group consisted of 8 healthy subjects individually matched with the PAH subjects for age, sex, and body mass index. None of the healthy subjects was taking medications.

\section{Study Design}

All the subjects were evaluated under the same conditions: in the morning, in the seated position, at rest for at least $20 \mathrm{~min}$, and without a meal for at least $8 \mathrm{~h}$. Peripheral microcirculation was measured with near-infrared spectroscopy and the 3-min vascular occlusion technique, as previously described. ${ }^{12-14,17,18}$ The healthy subjects and the chronic heart failure subjects underwent near-infrared spectroscopy while breathing room air. The PAH subjects underwent near-infrared spectroscopy in 3 conditions: while breathing room air; after $15 \mathrm{~min}$ of breathing $100 \%$ oxygen via non-rebreathing mask; and 15 min after stopping the oxygen inhalation. $\mathrm{S}_{\mathrm{pO}_{2}}$ and heart rate were continuously monitored during near-infrared spectroscopy.

\section{Near-Infrared Spectroscopy}

The use of near-infrared spectroscopy in humans has been previously validated. ${ }^{20}$ With a probe placed on the surface of the skin, near-infrared spectroscopy uses the principles of light spectroscopy to measure tissue $\mathrm{O}_{2}$ saturation, the percentage of hemoglobin saturation in all 3 tissue vascular compartments (arterial, capillary, venous). The light transmitted from the probe has a penetration depth of approximately $12.5 \mathrm{~mm}$, thus enabling measurement within the muscle.

We conducted near-infrared spectroscopy (InSpectra, Hutchinson Technology, Hutchinson, Minnesota) on the thenar muscle. Tissue $\mathrm{O}_{2}$ saturation (\%) was monitored continuously before, during, and after brachial artery occlusion with a pneumatic cuff inflated to $50 \mathrm{~mm} \mathrm{Hg}$ above the subject's systolic blood pressure, for $3 \mathrm{~min}$. Movement of the upper limb was not allowed during the measurements. The tissue $\mathrm{O}_{2}$ saturation curves were analyzed with the spectrascope's software (Inspectra Analysis 2.0, Hutchinson Technology, Hutchinson, Minnesota) running in statistics software (MatLab 7.0, MathWorks, Natick, Massachusetts). The first degree slope of the saturation curve during arterial occlusion was used to calculate the oxygen consumption rate (\%/min) (see Fig. 1). The first degree slope of the saturation curve after release of the brachial artery occlusion was used to calculate the reperfusion rate $(\% / \mathrm{min})$. Endothelial function was estimated by calculating the time needed for tissue $\mathrm{O}_{2}$ saturation to reach the highest value at the end of the occlusion period. Tissue oxygen restoration rate, another index of endothelial function, was calculated as the reactive hyperemia time, which is the time needed for tissue $\mathrm{O}_{2}$ saturation to return to baseline after the release of the occlusion.

\section{Statistical Analysis}

Continuous variables are presented as mean \pm SD. Prior to analysis, the continuous variables were tested with the 
Table 1. Baseline Characteristics of Subjects

\begin{tabular}{|c|c|c|c|}
\hline & $\begin{array}{c}\text { Pulmonary } \\
\text { Arterial Hypertension } \\
n=8\end{array}$ & $\begin{array}{c}\text { Chronic Heart Failure } \\
\qquad n=16\end{array}$ & $\begin{array}{c}\text { Controls } \\
n=8\end{array}$ \\
\hline Age, y & $53 \pm 15(52)$ & $57 \pm 12(58)$ & $55 \pm 14(51)$ \\
\hline Male/female & $2 / 6$ & $6 / 10$ & $2 / 6$ \\
\hline Body mass index, $\mathrm{kg} / \mathrm{m}^{2}$ & $23 \pm 4(23)$ & $26 \pm 4(24)$ & $24 \pm 3(23)$ \\
\hline \multicolumn{4}{|l|}{ New York Heart Association class, no. } \\
\hline 2 & 7 & 14 & \\
\hline 3 & 1 & 2 & \\
\hline Hemoglobin, g/dL & $14 \pm 4(16)$ & $13 \pm 2(12)$ & \\
\hline Creatinine, $\mathrm{mg} / \mathrm{dL}$ & $1.0 \pm 0.3(1.05)$ & $1.1 \pm 0.5(1.05)$ & \\
\hline Left-ventricular ejection fraction, $\%$ & $61 \pm 5(60)^{*}$ & $32 \pm 10(29)$ & \\
\hline Left-ventricular end diastolic diameter, $\mathrm{mm}$ & $48 \pm 9(48)^{*}$ & $66 \pm 7(67)$ & \\
\hline Pulmonary capillary wedge pressure, $\mathrm{mm} \mathrm{Hg}$ & $12 \pm 4(12)$ & & \\
\hline Systolic pulmonary arterial pressure, $\mathrm{mm} \mathrm{Hg}$ & $77 \pm 41(67)$ & & \\
\hline Diastolic pulmonary arterial pressure, $\mathrm{mm} \mathrm{Hg}$ & $34 \pm 18(26)$ & & \\
\hline Mean pulmonary arterial pressure, $\mathrm{mm} \mathrm{Hg}$ & $56 \pm 27(48)$ & & \\
\hline Cardiac output, $\mathrm{L} / \mathrm{min}$ & $5.8 \pm 3.0(4.8)$ & & \\
\hline Cardiac index, $\mathrm{L} / \mathrm{min} / \mathrm{m}^{2}$ & $3.4 \pm 1.8(2.5)$ & & \\
\hline
\end{tabular}

Kolmogorov-Smirnov test. Group means of continuous variables that showed a normal distribution were compared with the unpaired Student $t$ test. Continuous variables with non-normal distribution were compared with the non-parametric Mann-Whitney U test. Analysis of variance with post hoc Bonferroni multiple comparisons was performed for continuous variables for between-group differences (PAH vs chronic heart failure vs control). Repeated-measures analysis of variance was used to compare the within-group before, during, and after data. The level of significance was set at $P<.05$. The statistical analysis was performed with statistics software (SPSS 14.0, SPSS, Chicago, Illinois).

\section{Results}

There were no statistical differences in age, sex, or body mass index between the subjects and controls. The chronic heart failure subjects had lower left-ventricular ejection fraction and larger left-ventricular end-diastolic diameter than the PAH subjects $(P<.001)$.

\section{PAH Subjects Versus Healthy Subjects}

The subjects with $\mathrm{PAH}$ had significantly lower tissue $\mathrm{O}_{2}$ saturation and $\mathrm{S}_{\mathrm{pO}_{2}}$ than the control subjects $(P=.005$ and $P=.01$, respectively). The reactive hyperemia time was significantly longer in the PAH subjects than in the controls $(P<.001)$. There was no significant difference in oxygen consumption rate between the PAH subjects and the control subjects $(P=.60)$. There were trends toward a shorter time from lowest to highest tissue $\mathrm{O}_{2}$ saturation after occlusion $(P=.11)$ and reperfusion rate $(P=.06)$ in the PAH subjects, compared to the control subjects (Table 2).

\section{PAH Subjects Versus Chronic Heart Failure Subjects}

The PAH subjects had lower tissue $\mathrm{O}_{2}$ saturation $(P=.08)$ and $\mathrm{S}_{\mathrm{pO}_{2}}(P=.01)$, and higher reactive hyperemia time $(P=.02)$ than the chronic heart failure subjects (see Table 2). There was no significant difference in oxygen consumption rate between the $\mathrm{PAH}$ and chronic heart failure subjects.

\section{Tissue $\mathrm{O}_{2}$ Saturation in the PAH Subjects}

In the PAH subjects, after 15 min of breathing $100 \% \mathrm{O}_{2}$ there was a significant increase in tissue $\mathrm{O}_{2}$ saturation $(P=.01)$ and reactive hyperemia time (Fig. 2$)(P=.007)$, and a significant decrease in oxygen consumption rate $(P=.01)$, compared to the baseline values. All the measurements had a trend to return to baseline after discontinuation of oxygen (Table 3).

\section{Discussion}

This study shows that PAH patients are characterized by several skeletal muscle tissue microcirculation alterations, as assessed with near-infrared spectroscopy during vascu- 
Table 2. Near Infrared Spectroscopy Measurements During Vascular Occlusion

\begin{tabular}{|c|c|c|c|c|}
\hline & $\begin{array}{c}\text { Pulmonary } \\
\text { Arterial Hypertension } \\
n=8 \\
\text { mean } \pm \mathrm{SD} \\
\text { (median) }\end{array}$ & $\begin{array}{l}\text { Chronic Heart Failure } \\
n=16 \\
\text { mean } \pm \mathrm{SD} \\
(\text { median })\end{array}$ & $\begin{array}{l}\text { Controls } \\
n=8 \\
\text { mean } \pm \mathrm{SD} \\
\text { (median) }\end{array}$ & $\begin{array}{c}\text { ANOVA } \\
P\end{array}$ \\
\hline Tissue oxygen saturation, $\%$ & $65.8 \pm 14.9(69)^{*}$ & $75 \pm 7(76) \dagger$ & $82.1 \pm 4.0(82)$ & .006 \\
\hline Oxygen consumption rate, $\% / \mathrm{min}$ & $35.3 \pm 9.1(33)$ & $32 \pm 9(29)$ & $43.4 \pm 19.7(44)$ & .13 \\
\hline Reperfusion rate, $\% / \min$ & $535 \pm 176(573)$ & $548 \pm 137(558) \ddagger$ & $702 \pm 166(720)$ & .06 \\
\hline $\begin{array}{l}\text { Time from lowest to highest tissue oxygen } \\
\text { saturation at the end of the occlusion } \\
\text { period, min }\end{array}$ & $0.4 \pm 0.1(0.35)$ & $0.4 \pm 0.1(0.35) \S$ & $0.28 \pm 0.05(0.23)$ & .05 \\
\hline Reactive hyperemia time, min & $3.0 \pm 0.6(3.0) \|$ & $2.4 \pm 0.5(2.5) \mathbb{I}$ & $2.0 \pm 0.3(2.0)$ & .001 \\
\hline $\mathrm{S}_{\mathrm{pO}_{2}}, \%$ & $90 \pm 7(94)^{* *}$ & $97 \pm 1(97)$ & $98 \pm 1(98)$ & $<.001$ \\
\hline Heart rate, beats/min & $74 \pm 13(73)$ & $67 \pm 9(65)$ & $69 \pm 2(69)$ & .69 \\
\hline $\begin{array}{l}\text { Values are mean } \pm \mathrm{SD} \text { (median). } \\
\text { Bonferroni post-hoc analysis between groups: } \\
* P=.005 \text { for pulmonary arterial hypertension (PAH) vs } \\
\dagger P=.08 \text { for PAH vs chronic heart failure. } \\
¥ P=.09 \text { for PAH vs chronic heart failure. } \\
\S P=.06 \text { for chronic heart failure vs controls. } \\
\| P<.001 \text { for PAH vs controls. } \\
\mathbb{\Psi} P=.02 \text { for PAH vs chronic heart failure. } \\
* * P=.01 \text { for PAH vs chronic heart failure, and for PAH }\end{array}$ & & & & \\
\hline
\end{tabular}

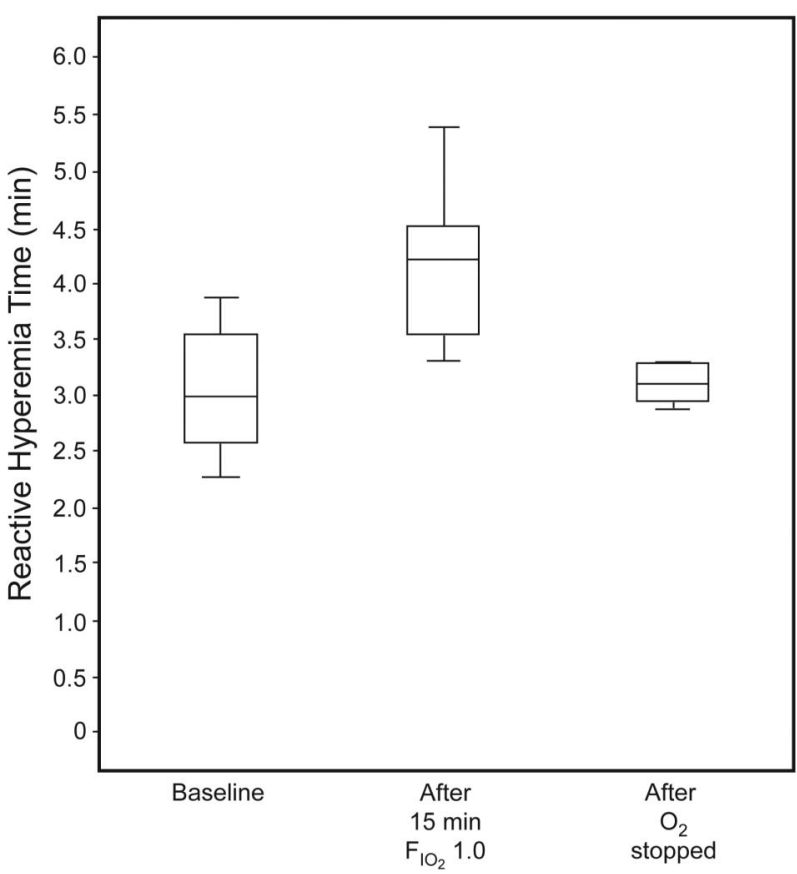

Fig. 2. Reactive hyperemia time before, during, and after breathing $100 \%$ oxygen, in subjects with pulmonary arterial hypertension. $P=.007$ for baseline versus after $15 \mathrm{~min}$ of $100 \% \mathrm{O}_{2} . P=.02$ for after 15 min of $100 \% \mathrm{O}_{2}$ versus 15 min after $\mathrm{O}_{2}$ discontinuation. In each data bar, the horizontal line represents the median, the top and bottom of the bar represents the interquartile range, and the whisker bars represent the range.

lar occlusion. More specifically, the PAH subjects had a lower resting skeletal muscle tissue oxygenation, a trend toward a decreased oxygen consumption rate, and a slower tissue oxygen restoration rate during reperfusion than did the control subjects. The PAH subjects also had a slower tissue oxygen restoration rate and a trend toward a lower resting skeletal muscle tissue oxygenation than the chronic heart failure subjects, who were matched with the PAH subjects for exercise capacity.

By applying the near-infrared spectroscopy with occlusion technique we have assessed several novel aspects of peripheral tissue microcirculation in PAH subjects, monitoring in this way tissue microcirculation changes during hyperoxic breathing. To our knowledge, this study is the first to evaluate skeletal muscle microcirculation with near-infrared spectroscopy and vascular occlusion in PAH subjects, and to monitor systemic microcirculation changes after chemo-reflex deactivation.

Recent studies have found impaired peripheral endothelial function in subjects with $\mathrm{PAH}$, in relation to disease severity. ${ }^{7-9}$ Endothelium function was measured with ultrasound during brachial artery flow-mediated vasodilatation during reactive hyperemia ${ }^{7}$ and with noninvasive plethysmography assessing post-occlusion brachial artery flow-mediated vasodilatation. ${ }^{8,9}$ Our study confirms those findings related to endothelium dysfunction in $\mathrm{PAH}$ subjects.

In our study the resting tissue oxygen saturation differences between PAH subjects and healthy subjects can be explained mainly by the hypoxemia in the PAH subjects, which decreases oxygen delivery and tissue oxygen saturation. Low cardiac output in PAH might also be a con- 
Table 3. Near Infrared Spectroscopy Measurements Before, During, and After Supplemental Oxygen in Subjects With Pulmonary Arterial Hypertension

\begin{tabular}{|c|c|c|c|}
\hline & $\begin{array}{c}\text { Baseline } \\
\left(\mathrm{F}_{\mathrm{IO}_{2}} 0.21\right)\end{array}$ & $\begin{array}{l}\text { After } 15 \text { Min With } \\
\mathrm{F}_{\mathrm{IO}_{2}} 1.0\end{array}$ & $\begin{array}{l}15 \text { Min After } \mathrm{O}_{2} \\
\text { Discontinuation }\end{array}$ \\
\hline Tissue oxygen saturation, $\%$ & $65.8 \pm 14.9(69)$ & $71.4 \pm 14.5(74)^{*}$ & $63.9 \pm 14.8(68) \dagger$ \\
\hline Oxygen consumption rate, $\% / \mathrm{min}$ & $35.3 \pm 9.1(33)$ & $25.1 \pm 6.6(25)^{*}$ & $31.3 \pm 13.3(27)$ \\
\hline Reperfusion rate, $\% / \min$ & $535 \pm 176(573)$ & $601 \pm 162(654)$ & $619 \pm 209(609)$ \\
\hline $\begin{array}{l}\text { Time from lowest to highest tissue oxygen } \\
\text { saturation at the end of the occlusion } \\
\text { period, min }\end{array}$ & $0.4 \pm 0.1(0.35)$ & $0.35 \pm 0.12(0.28)$ & $0.36 \pm 0.16(0.29)$ \\
\hline Reactive hyperemia time, $\min$ & $3.0 \pm 0.6(3.0)$ & $4.2 \pm 0.7(4.2) \ddagger$ & $3.1 \pm 0.2(3.1) \S$ \\
\hline $\mathrm{S}_{\mathrm{pO}_{2}}, \%$ & $90 \pm 7(94)$ & $95 \pm 6(98) \ddagger$ & $91 \pm 8(95) \S$ \\
\hline Heart rate, beats/min & $74 \pm 13(73)$ & $68 \pm 10(67)^{*}$ & $72 \pm 11(70) \|$ \\
\hline \multicolumn{4}{|c|}{ 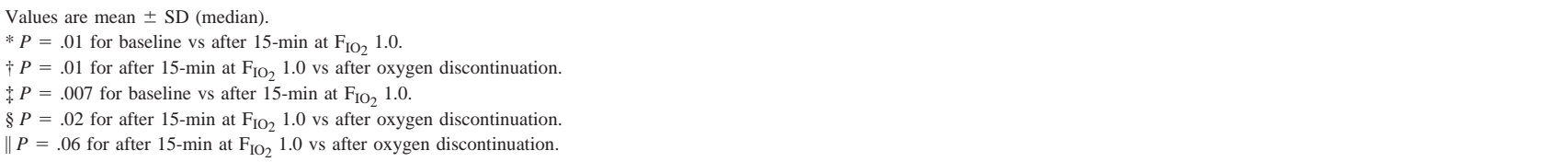 } \\
\hline
\end{tabular}

tributing factor. Low tissue oxygen saturation is related to disease severity in patients with chronic left-ventricular dysfunction, and can be improved with intravenous inotropic agents ${ }^{13}$ and by exercise training. ${ }^{14}$ In our study the PAH subjects had lower tissue oxygen saturation than the chronic heart failure subjects, but PAH subjects did not have low cardiac output, making it less likely that low cardiac output was the cause of their tissue oxygen saturation. Another possible explanation might be increased sympathetic tone in $\mathrm{PAH}$, which decreases tissue perfusion. Interestingly, recent studies have shown increased sympathetic nerve activity ${ }^{21}$ and impaired autonomic nervous activity, which is related to disease severity, ${ }^{22,23}$ in PAH patients.

During vascular occlusion we found a trend toward a decreased oxygen consumption rate in the PAH subjects, compared to the control subjects, indicating a relatively low tissue oxygen diffusion rate, possibly due to skeletal muscle abnormalities (reduction of oxidative muscle fibers, depletion of mitochondria). This might be explained by the presence of skeletal muscle atrophy due to chronic low tissue perfusion and deconditioning in PAH patients. Recent studies have shown substantial skeletal muscle dysfunction in PAH patients. ${ }^{24,25}$ Imbalance between vasoconstrictor and vasodilator microvascular tone regulated mainly by local (endothelial function) and systemic neuro-humoral factors seems to be the main reason for the slower tissue oxygen restoration rate during reperfusion in PAH patients. In PAH there is an imbalance between the excretion of thromboxane and prostacyclin metabolites, ${ }^{6}$ decreased nitric oxide synthase, ${ }^{5}$ and high plasma endothelin-1. ${ }^{4}$ Endothelium dysfunction plays a central role in the initiation and progression of $\mathrm{PAH} .{ }^{3}$ Gabrielli et al ${ }^{26}$ recently found that adults with PAH have increased oxidative stress and endothelial dysfunction markers. Friedman et $\mathrm{al}^{27}$ found that children with idiopathic PAH have substantial systemic endothelial dysfunction, in association with disease severity. However, whether those abnormalities in systemic endothelium function affect the PAH disease process or are a consequence of PAH is not yet known. Further longitudinal studies are needed to investigate the exact mechanism. Another important finding in our study is that supplemental oxygen improves resting skeletal muscle tissue oxygenation, while decreasing the oxygen consumption rate and the tissue oxygen restoration rate in $\mathrm{PAH}$ subjects.

The acute changes of peripheral tissue microcirculation with oxygen supplementation in PAH subjects consisted of improving resting tissue oxygen saturation, mainly as an expression of higher oxygen delivery due to improved hypoxemia, and less possibly to higher cardiac output. The acute correction of hypoxemia induces a slight reduction in sympathetic activity in PAH patients, ${ }^{21,28}$ which indirectly reduces the stiffness of the main pulmonary artery, ${ }^{28}$ lowering right-ventricular after-load. However, studies in healthy subjects found that high $\mathrm{F}_{\mathrm{IO}_{2}}$ induces a vagusdependent decrease in heart rate, a rate-dependent decrease in cardiac index, and an increase in peripheral systemic resistance. ${ }^{29-32}$

Interestingly, the oxygen consumption rate was slowed, and there was a more pronounced delay in the tissue oxygen restoration rate after hyperoxic breathing, suggesting deterioration in peripheral tissue microcirculation in PAH subjects. The exact mechanism of these changes is not known, but a possible explanation is increased oxidative stress, the formation of reactive oxygen species, and the peripheral vasoconstriction induced by high $\mathrm{F}_{\mathrm{IO}_{2}}{ }^{29}$ The latter mechanism has also been proposed by recent inves- 
tigators who used flow-mediated vasodilatation assessment in conductance arteries and in the microvasculature in healthy adults ${ }^{30}$ and in patients with high cardiovascular risk. ${ }^{31}$ In a previous important study it was shown that pulmonary vascular resistance decreased and systemic vascular resistance increased after hyperoxic breathing in patients with severe pulmonary vascular obstructive disease, the effect being more pronounced on the systemic than on the pulmonary vascular bed. ${ }^{33}$ Furthermore, as recent systemic reviews have shown, high $\mathrm{F}_{\mathrm{IO}_{2}}$ markedly reduces coronary blood flow and myocardial oxygen consumption, ${ }^{34}$ while there is limited evidence of routine use of oxygen therapy in uncomplicated myocardial infarction. ${ }^{35}$ Interestingly, in a recent study detrimental effects of oxygen therapy were noted in patients with heart failure. ${ }^{36}$ The risk of detrimental effects from high $\mathrm{F}_{\mathrm{IO}_{2}}$ on peripheral tissue microcirculation must be the aim of future studies to establish the benefits and safety limits of oxygen supplementation in PAH patients, and near-infrared spectroscopy during arterial occlusion might be a useful tool in that research.

\section{Clinical Implications}

PAH patients present with several abnormalities in peripheral tissue microcirculation that can be detected with near-infrared spectroscopy during arterial occlusion. Oxygen supplementation induces changes in peripheral tissue microcirculation of PAH patients that can be evaluated and monitored with near-infrared spectroscopy. This simple, noninvasive technique provides valuable information for monitoring and prognosis, and may detect PAH patients with worse peripheral tissue microcirculation abnormalities, who might benefit from endothelin antagonists, prostanoid analogs, phosphodiesterase inhibitors, angiotensin-converting enzyme inhibitors, oxygen therapy, and/or exercise training.

\section{Limitations}

Our small number of PAH subjects did not allow us to study a possible correlation with disease severity. While we did not directly evaluate endothelium function, we used the near-infrared spectroscopy during arterial occlusion as an indirect evaluation of peripheral tissue microcirculation. A non-significantly lower oxygen consumption rate was found in the PAH subjects than in the controls. This was possibly due to the small number of PAH subjects. We did not provide cardiac output in the chronic heart failure subjects, because only a few of these subjects had had a recent right-heart catheterization. However, the chronic heart failure group might have had a rather low cardiac output, compared to the PAH group, which had a normal cardiac output (see Table 2). Also, the PAH sub- jects were receiving endothelin antagonists and sildenafil, which might have affected our results. However, endothelin antagonists and sildenafil are potent vasodilators that improve endothelial function, so this treatment enhances rather than favors the negative findings in our PAH subjects. We identified systemic microcirculation changes in the PAH subjects by comparing their results to those of healthy subjects, but the exact cause of these findings cannot be confirmed by our study, so future studies are required.

\section{Conclusions}

PAH patients have alterations in peripheral tissue microcirculation, as assessed with near-infrared spectroscopy during arterial occlusion. Specifically, PAH patients exhibit decreased tissue oxygen saturation, possibly due to hypoxemia, and a slower tissue oxygen restoration rate, possibly due to endothelium dysfunction and peripheral vasoconstriction in the systemic microcirculation. High $\mathrm{F}_{\mathrm{IO}_{2}}$ improved the resting tissue oxygen saturation, as an expression of higher oxygen delivery, and decreased the tissue oxygen consumption rate and tissue oxygen restoration rate during reperfusion, possibly due to increased oxidative stress and evoked vasoconstriction.

\section{REFERENCES}

1. Thenappan T, Shah SJ, Rich S, Gomberg-Maitland M. A USA-based registry for pulmonary arterial hypertension 1982-2006. Eur Respir J 2007;30(6):1103-1110.

2. McLaughlin VV, Archer SL, Badesch DB, Barst RJ, Farber HW, Lindner JR, et al; American College of Cardiology Foundation Task Force on Expert Consensus Documents; American Heart Association; American College of Chest Physicians; American Thoracic Society; Pulmonary Hypertension Assocation. ACCF/AHA 2009 expert consensus document on pulmonary hypertension. Circulation 2009;119(16):2250-2294. Erratum in: Circulation 2009;120(2):e13.

3. Budhiraja R, Tuder RM, Hassoun PM. Endothelial dysfunction in pulmonary hypertension. Circulation 2004;109(2):159-165.

4. Stewart DJ, Levy RD, Cernacek P, Langleben D. Increased plasma endothelin-1 in pulmonary hypertension: marker or mediator of disease? Ann Intern Med 1991;114(6):464-469.

5. Giaid A, Saleh D. Reduced expression of endothelial nitric oxide synthase in the lungs of patients with pulmonary hypertension. N Engl J Med 1995;333(4):214-221.

6. Christman BW, McPherson CD, Newman JH, King GA, Bernard GR, Groves BM, Loyd JE. An imbalance between the excretion of thromboxane and prostacyclin metabolites in pulmonary hypertension. N Engl J Med 1992;327(2):70-75.

7. Wolff B, Lodziewski S, Bollmann T, Opitz CF, Ewert R. Impaired peripheral endothelial function in severe idiopathic pulmonary hypertension correlates with the pulmonary vascular response to inhaled iloprost. Am Heart J 2007;153(6):1088.e1-e7.

8. Peled N, Bendayan D, Shitrit D, Fox B, Yehoshua L, Kramer MR. Peripheral endothelial dysfunction in patients with pulmonary arterial hypertension. Respir Med 2008;102(12):1791-1796.

9. Peled N, Bendayan D, Shitrit D, Fox B, Yehoshua L, Kramer MR. Peripheral arterial stiffness and endothelial dysfunction in idiopathic 
and scleroderma associated pulmonary arterial hypertension. J Rheumatol 2009;36(5):970-975.

10. Badesch DB, Abman SH, Simonneau G, Rubin LJ, McLaughlin VV. Medical therapy for pulmonary arterial hypertension: updated ACCP evidence-based clinical practice guidelines. Chest 2007; 131(6):1917-1928.

11. De Blasi RA, Cope M, Elwell C, Safoue F, Ferrari M. Non-invasive measurement of human forearm oxygen consumption by near infrared spectroscopy. Eur J Appl Physiol Occup Physiol 1993;67(1): 20-25.

12. Siafaka A, Angelopoulos E, Kritikos K, Poriazi M, Basios N, Gerovasili V, et al. Acute effects of smoking on skeletal muscle microcirculation monitored by near-infrared spectroscopy. Chest 2007;131(5):1479-1485.

13. Nanas S, Gerovasili V, Dimopoulos S, Pierrakos C, Kourtidou S, Kaldara E, et al. Inotropic agents improve the peripheral microcirculation of patients with end-stage chronic heart failure. J Card Fail 2008;14(5):400-406.

14. Gerovasili V, Drakos S, Kravari M, Malliaras K, Karatzanos E, Dimopoulos S, et al. Physical exercise improves the peripheral microcirculation of patients with chronic heart failure. J Cardiopulm Rehabil Prev 2009;29(6):385-391.

15. Abozguia K, Phan TT, Shivu GN, Maher AR, Ahmed I, Wagenmakers A, Frenneaux MP. Reduced in vivo skeletal muscle oxygen consumption in patients with chronic heart failure: a study using Near Infrared Spectrophotometry (NIRS). Eur J Heart Fail 2008; 10(7):652-657.

16. Nanas S, Gerovasili V, Renieris P, Angelopoulos E, Poriazi M, Kritikos K, et al. Non invasive assessment of the microcirculation in critically ill patients. Anaesth Intensive Care 2009;37(5):700-702.

17. Gerovasili V, Dimopoulos S, Tzanis G, Anastasiou-Nana M, Nanas S. Utilizing the vascular occlusion technique with NIRS technology. Int J Ind Ergon 2010;40(2):218-222.

18. Manetos C, Dimopoulos S, Tzanis G, Vakrou S, Tasoulis A, Kapelios $\mathrm{C}$, et al. Skeletal muscle microcirculatory abnormalities are associated with exercise intolerance, ventilatory inefficiency, and impaired autonomic control in heart failure. J Heart Lung Transplant 2011;30(12):1403-1408.

19. Shewan LG, Coats AJ. Ethics in the authorship and publishing of scientific articles. Int J Cardiol 2010;144(1):1-2.

20. Mancini DM, Bolinger L, Li H, Kendrick K, Chance B, Wilson JR. Validation of near infrared spectroscopy in humans. J Appl Physiol 1994;77(6):2740-2747.

21. Velez-Roa S, Ciarka A, Najem B, Vachiery JL, Naeije R, van de Borne P. Increased sympathetic nerve activity in pulmonary artery hypertension. Circulation 2004;110(10):1308-1312.

22. Dimopoulos S, Anastasiou-Nana M, Katsaros F, Papazachou O, Tzanis G, Gerovasili V, et al. Impairment of autonomic nervous system activity in patients with pulmonary arterial hypertension: a case control study. J Cardiac Fail 2009;15(10):882-889.
23. Wensel R, Jilek C, Dörr M, Francis DP, Stadler H, Lange T, et al. Impaired cardiac autonomic control relates to disease severity in pulmonary hypertension. Eur Respir J 2009;34(4):792-794.

24. Bauer R, Dehnert C, Schoene P, Filusch A, Bärtsch P, Borst MM, et al. Skeletal muscle dysfunction in patients with idiopathic pulmonary arterial hypertension. Respir Med 2007;101(11):2366-2369.

25. Mainguy V, Maltais F, Saey D, Gagnon P, Martel S, Simon M, Provencher S. Peripheral muscle dysfunction in idiopathic pulmonary arterial hypertension. Thorax 2010;65(2):113-117.

26. Gabrielli LA, Castro PF, Godoy I, Mellado R, Bourge RC, Alcaino $\mathrm{H}$, et al. Systemic oxidative stress and endothelial dysfunction is associated with an attenuated acute vascular response to inhaled prostanoid in pulmonary artery hypertension patients. J Card Fail 2011;17(12):1012-1017.

27. Friedman D, Szmuszkovicz J, Rabai M, Detterich JA, Menteer J, Wood JC. Systemic endothelial dysfunction in children with idiopathic pulmonary arterial hypertension correlates with disease severity. J Heart Lung Transplant 2012;31(6):642-647.

28. Haneda T, Nakajima T, Shirato K, Onodera S, Takishima T. Effects of oxygen breathing on pulmonary vascular input impedance in patients with pulmonary hypertension. Chest 1983;83(3):520-527.

29. Daly WJ, Bondurant S. Effects of oxygen breathing on the heart rate, blood pressure, and cardiac index of normal men, resting, with reactive hyperemia, and after atropine. J Clin Invest 1962;41:126-132.

30. Waring WS, Thomson AJ, Adwani SH, Rosseel AJ, Potter JF, Webb DJ, Maxwell SR. Cardiovascular effects of acute oxygen administration in healthy adults. J Cardiovasc Pharmacol 2003;42(2): 245-250.

31. Frøbert O, Holmager P, Jensen KM, Schmidt EB, Simonsen U. Effect of acute changes in oxygen tension on flow-mediated dilation. Relation to cardiovascular risk. Scand Cardiovasc J 2008;42(1): 38-47.

32. Gole Y, Gargne O, Coulange M, Steinberg JG, Bouhaddi M, Jammes $\mathrm{Y}$, et al. Hyperoxia-induced alterations in cardiovascular function and autonomic control during return to normoxic breathing. Eur J Appl Physiol 2011;111(6):937-946.

33. Krongrad E, Helmholz HF, Ritter DG. Effect of breathing oxygen in patients with severe pulmonary vascular obstructive disease. Circulation 1973;47(1):94-100.

34. Wijesinghe M, Perrin K, Ranchord A, Simmonds M, Weatherall M, Beasley R. Routine use of oxygen in the treatment of myocardial infarction: systematic review. Heart 2009;95(3):198-202.

35. Farquhar H, Weatherall M, Wijesinghe M, Perrin K, Ranchord A, Simmonds M, Beasley R. Systematic review of studies of the effect of hyperoxia on coronary blood flow. Am Heart J 2009;158(3): 371-377.

36. Park JH, Balmain S, Berry C, Morton JJ, McMurray JJ. Potentially detrimental cardiovascular effects of oxygen in patients with chronic left ventricular systolic dysfunction. Heart 2010;96(7):533-538. 